\title{
Analysis of Farmers Adoption Behaviour of CRIG Recommended Technologies as a Package: The Case of Some Self Help Cocoa Farmer Associations in the Eastern Region of Ghana
}

\author{
Asamoah Mercy*, Francis Aneani, Samuel Ofori, Prince F. Branor \\ Cocoa Research Institute of Ghana (Crig), New-Tafo, Ghana \\ Email: ${ }^{*}$ mrcyasamoah@yahoo.com, mrcyasamoah@gmail.com
}

Received 19 March 2015; accepted 27 June 2015; published 30 June 2015

Copyright (C) 2015 by authors and Scientific Research Publishing Inc.

This work is licensed under the Creative Commons Attribution International License (CC BY).

http://creativecommons.org/licenses/by/4.0/

c) (i) Open Access

\begin{abstract}
Adoption of recommended technologies as a package is the prelude to increase cocoa productivity per unit area. This is due to the interactive benefits of individual technologies which have been recommended by the Cocoa Research Institute of Ghana (CRIG). However, many surveys among cocoa farmers have reported low adoption of technologies resulting in low productivity of cocoa with an average of $450 \mathrm{~kg} / \mathrm{ha}$ among small holder cocoa farmers in Ghana. The current study investigates the adoption behavior of some cocoa farmers belonging to some self help farmer associations in the Eastern Region who are being monitored by CRIG since 2011. Primary data was collected from 131 respondents using questionnaires to interview farmers between 2013 and 2015. The results showed that adoption of recommended cocoa technologies as a package was still low. Respondents, however, identified a number of challenges including high cost of inputs, lack of finance and access to credit, high cost of labour and old age as some factors hampering composite adoption of the full CRIG technologies. It is recommended that small-scale cocoa farmers need a sustainable and convenient microfinance that can motivate and help them afford the cost associated with the full package of technologies. Farmers' savings culture should also be nurtured to enhance their financial capabilities and investment in the cocoa farm.
\end{abstract}

\section{Keywords}

Cocoa, Small-Scale Farmers, Adoption, Technologies, Microfinance

${ }^{*}$ Corresponding author.

How to cite this paper: Asamoah, M., Aneani, F., Ofori, S. and Branor, P.F. (2015) Analysis of Farmers Adoption Behaviour of CRIG Recommended Technologies as a Package: The Case of Some Self Help Cocoa Farmer Associations in the Eastern Region of Ghana. Agricultural Sciences, 6, 601-608. http://dx.doi.org/10.4236/as.2015.66059 


\section{Introduction}

Ghana remained the world's largest cocoa producer till the early 1960's (Bulir, 2002) [1]. Between the 1960s and the 1980s, Ghana's cocoa output declined by 60\%. By the beginning of the 1980s, Ghana's production dropped significantly from an average of more than 400,000 tonnes per year to a low of 270,000 tonnes between 1988-1990 (CRIG Handbook, 2010) [2]. This fall was attributed to many factors, including widespread occurrences of pests and diseases, aging of cocoa trees and producers, bad weather conditions, poor extension support and low producer prices. Cocoa production picked up due in part to government-backed rehabilitation programmes, such as the nation-wide control of pests and diseases programme (CODAPEC), fertilizer application (Hi-Tech) and replanting of old farms from the year 2000 (International Cocoa Organisation, 2007 [3], Opoku et al., 2007 [4]). Regardless of the gains, however, low cocoa productivity still persists (Baah et al., 2011) [5] with average yield hovering around 450kg per hectare on small holder farms against potential yields of 2.5 tonnes per hectare obtained on farms where all research (CRIG) ${ }^{1}$ recommendations are applied. Several factors affect cocoa productivity including the adoption of the full package of recommendations. Earlier studies (e.g., Henderson et al., 1990 [6]; Donkor et al., 1991 [7]; Asante, 1992 [8]; Asamoah, 2001 [9]; Baah et al., 2011 [5]; Aneani, 2012 [10]) have reported low adoption rate of CRIG recommended technologies by cocoa farmers in Ghana over the years, a situation which needs to be addressed for the sake of the sustainability of cocoa production.

CRIG has developed technologies for cocoa pests and diseases management, weed control (manually and chemically) and soil amelioration (by applying fertilizer) whose synergistic effect enhance cocoa productivity. Yet, small holder farmers are unable to adopt all the technologies in full to derive maximum benefit due to many socio-economic reasons including low productivity, lack of access to credit and extension services. To address these challenges, some farmers were facilitated by the social science staff of CRIG to form farmer associations in order to get technical knowledge to improve their cocoa production since 2011. The objectives of this study are thus, to determine the farmers' adoption behavior of CRIG recommended technologies (as a package or selectively), to identify current constraints to composite adoption and to determine the effect of some socio-economic characteristics such as age, farm size, farmer education and outreach on adoption behavior.

\section{Research Method}

The study was conducted in seven communities within three cocoa growing districts namely Tafo, Osino and Birim North in the Eastern Region between 2013 and 2015. Primary data was collected with the administration of a well structured and pretested questionnaire among members of some farmer associations being monitored over four years by CRIG. In order to get accurate productivity data, 131 cocoa farms were measured using Geographical Positioning System (GPS). After measurement, the owners of the farms were interviewed for data on Socio-economic characteristics, agronomic and other farm maintenance practices. The variables included farmer and farm ages, educational levels, total income, frequency of application of recommended technologies and constraints among others.

In order to measure farmers' adoption status, the authors computed adoption index from farm management technologies recommended by CRIG for cocoa farmers. Adoption was operationally defined as the full use of all CRIG recommendations for cocoa cultivation at the right time, frequency, with the right equipment and approved chemicals. The technologies being measured in this study were weed control at least two to four times a year depending on the age and maturity of the farm, frequent pruning and Chupon removal at least two times a year. Others are the control of capsids with approved insecticides four times a year, control of black pod diseases with approved fungicides six to nine times a year, fertilizer application once a year for three to four consecutive years and removal of mistletoe at least two times a year. Thereafter, a total adoption score of all the recommended technologies indicated above were calculated. A score of 23 - 27 was classified as full adoption for a young farm (zero to 7 years) while a score of 26 - 30 is for matured farms aged eight to 30 years and above (Table 1(a) \& Table 1(b)). Based on the farm age and total adoption score, a farmer's adoption status was determined as non-adopters, low, medium or high adopters (Table 1(b)). Farms were also classified as:

1) Young farm (a farm which is less than seven years old)

2) Mature, but, fairly young (a farm between eight and 15 years)

3) Mature (a farm between 16 and 30 years) and

\footnotetext{
${ }^{1}$ Cocoa Research Institute of Ghana.
} 
Table 1. (a) Frequency of adoption of cocoa farm practices recommended by CRIG for farmers; (b) Age of farm and corresponding total score for adoption classification by respondents.

(a)

\begin{tabular}{ccccccccc}
\hline \multirow{2}{*}{$\begin{array}{c}\text { Age of farm } \\
\text { (years) }\end{array}$} & Weeding & Pest control & $\begin{array}{c}\text { Recommended Practices } \\
\text { Disease control } \\
\text { (black pod) }\end{array}$ & Pruning & Mistletoe & $\begin{array}{c}\text { Chupon } \\
\text { removal }\end{array}$ & $\begin{array}{c}\text { Fertilizer } \\
\text { *** }\end{array}$ & $\begin{array}{c}\text { Total adoption } \\
\text { score }\end{array}$ \\
\hline $0-7$ & 4 & 4 & $6-9$ & 2 & $1-2$ & 6 & - & $23-27$ \\
$8-15$ & 2 & 4 & $6-9$ & 2 & 3 & 6 & 3 & $26-29$ \\
$16-30$ & 2 & 4 & $6-9$ & 2 & 4 & 6 & 3 & $26-29$ \\
$>30$ & 2 & 4 & $6-9$ & 2 & 4 & 6 & 3 & $27-30$ \\
\hline
\end{tabular}

*Authors computation from CRIG hand-books/research findings; ${ }^{* *}$ Note: Fertilizer is to be applied continuously for three to four times on the same piece of land in order to realize its full potential.

(b)

\begin{tabular}{ccccc}
\hline Age of cocoa farm & High & Medium & Low & Non-Adoption \\
\hline $0-7$ & $23-27$ & $16-22$ & $9-15$ & $<9$ \\
$8-15$ & $26-29$ & $18-25$ & $10-17$ & $<10$ \\
$16-30$ & $26-29$ & $18-25$ & $10-17$ & $<10$ \\
$>30$ & $27-30$ & $18-25$ & $10-17$ & $<10$ \\
\hline
\end{tabular}

Source: Authors computation from CRIG hand-books/research findings. Data was descriptively analyzed with the use of a Statistical Product for Service Solution (SPSS).

4) Very mature and need rehabilitation (a farm above 30 years old).

\section{Results and Discussions}

\subsection{Personal Characteristics of Respondents}

Mean age of the farmers was 54 years, with the minimum being 20 and the maximum 80 years. About $56 \%$ were 41 - 60 years old with only less than $14 \%$ that could be classified as the youth (Table 2). Mean ages in many socio-economic studies of farmers have been above 50 years (MASDAR, 1998 [11], Baah and Asamoah, 2005 [12]; 2007; 2013 [13] [14]; Aneani et al. 2012 [10]). This is a worrying situation to some aged farmers since the future of their cocoa farms depend on the interest of the youth who are their potential heirs.

Educational status of the farmers was also low, as the majority (71\%) had basic education or none at all (8\%) (Table 2). This is also consistent with earlier studies (MASDAR, 1998, Baah and Asamoah 2003 [12], Asamoah, 2006; 2013 [13] [14]; Aneani et al. 2012 [10]).

In terms of gender, $70 \%$ of them were male farmers while $30 \%$ were females, indicating that cocoa is still predominantly male activity. The majority (77.9\%) of the farmers were married with average household size of seven members; the minimum being one and the maximum, 20 members. Also, 50.4\% of the respondents were owner operators. This means that they were managing the cocoa farms themselves irrespective of their old age. About 28\% were abunu sharecroppers (i.e. sharing of proceeds from dry cocoa beans between the owner and caretaker equally ) while about $22 \%$ were abusa sharecroppers (i.e. tripartite sharing system where the owner takes two thirds and the caretaker takes one third of the proceeds from the dry cocoa beans). These sharing systems of the proceeds have serious implications for cost sharing, decision making for adoption of technologies and motivation to adopt full technologies since most of the technologies depend on large capital outlay. Abusa sharecroppers only implement the decisions of farm owners and are limited financially to adopt recommendations fully. The results show that the majority of them managed more than one cocoa farm located at different geographical locations with the exception of about $22 \%$ that maintained only one farm. It is important to note that all these characteristics of the respondents discussed have telling effect on decision making, time and ability to adopt recommendations fully as a package. 
Table 2. Personal characteristics of respondents.

\begin{tabular}{|ccc|}
\hline & Age of profile of the respondents & \\
\hline Ages & Frequency & Percentage (\%) \\
\hline $20-40$ & 18 & 13.7 \\
$41-60$ & 73 & 55.7 \\
\hline $60+$ & 40 & 30.5 \\
\hline No formal education & Level of Education of respondents & \\
\hline Basic level & 11 & 8.0 \\
Secondary level & 93 & 71.0 \\
Tertiary level & 22 & 17.0 \\
\hline
\end{tabular}

Source: Field data (2013).

\subsection{Cocoa Farm Sizes: Implications for Cost of Composite Adoption of CRIG Technologies}

Another feature of cocoa farmers which have implications for full adoption is the inability to know the actual sizes of cocoa farms. There was a significant $(p=0.000)$ variation between the perceived and actual farm sizes of the respondents. While average perceived farm size was 1.64 hectares, GPS measured had average (actual) farm size of 1.49 hectares. This difference of 0.2 hectare for instance, may have significant effect on input-output relationship and yield. Table 3 gives details of perceived and actual farm sizes by respondents.

While $18.3 \%$ of the farmers did not even know their farm sizes, $44.8 \%$ (instead of $25.2 \%$ ) had farms which were less than one hectare $(0.2$ - 0.9 ha). Similarly, $2.3 \%$ more farmers did not know that their farms were between 3.0 - 4.9 ha. Wrong perception of farm sizes will thus, lead to over or under estimating the input required for a particular cocoa farm leading to ineffectiveness, inefficiency, high cost of the input on one hand, and discouragement and poor adoption behaviour on the part of the farmer. It is therefore important for every farmer to accurately measure the farm size as a matter of rational economic decision making. CRIG has long established the interactive effect and benefits of composite rather than selective adoption of technologies (Asante 1992 [8]) and farmers should be encouraged to change their investment and adoption behavior towards best farm management practices for increased yield.

\subsection{Production Levels of Respondents (kg/ha)}

Another factor that affects full adoption of technologies is yield which translates into income for the farmer. Many studies (Asamoah, 2001; [9], Asamoah, 2013 [14], Aneani et al., 2012 [10]) have indicated that cocoa constitutes a large proportion of cocoa farmers' income. Unfortunately, the results revealed that most of the farmers had low yield (consistent with previous studies) which leads to low income with its ripple effect on their ability to adopt technologies in full (Table 4). About 62\% have yield less than $500 \mathrm{~kg} / \mathrm{ha}$ (Table 4), while only less than $8 \%$ had $850 \mathrm{~kg} / \mathrm{ha}$ or more, which is a worrying phenomenon among small holder cocoa farmers in Ghana.

\subsection{Adoption Status of CRIG Technologies as a Package and Effect of Personal Characteristics}

Out of 120 farmers whose farms were eight years and above and measured with GPS, the majority was classified as low or non-adopters (Figure 1). Only a few had adopted all the CRIG recommendations being measured as a package over the three year period (Figure 1). This has serious implications for sustainable cocoa cultivation and enhanced farmer livelihood since full package or high adoption is expected to have significant impact on cocoa production and farmers' income. Adoption changed slightly across the categories from none to high (Figure 1) over the years. This low adoption trend is consistent with earlier studies on adoption by the author (Asamoah, 2001 [9]) where full adopters were less than ten percent of the sample. Nonetheless, the slight change 
Table 3. Respondent's sizes of cocoa farms in hectares.

\begin{tabular}{ccc}
\hline Farm sizes (Ha) & $\begin{array}{c}\text { \% of respondents giving } \\
\text { perceived sizes }\end{array}$ & $\begin{array}{c}\text { \% of respondents with farms } \\
\text { measured with GPS }\end{array}$ \\
\hline $0.2-0.9$ & 25.2 & 44.8 \\
$1.0-2.9$ & 48.8 & 45.8 \\
$3.0-4.9$ & 5.3 & 7.6 \\
5 or more & 2.3 & 2.3 \\
Don't know the size & 18.3 & - \\
\hline
\end{tabular}

Source: Field data (2013).

Table 4. Cocoa production levels of respondents (kg/ha).

\begin{tabular}{ccc}
\hline Production level & Frequency & Percentage (\%) \\
\hline $50-499$ & 81 & 61.8 \\
$500-849$ & 39 & 29.8 \\
850 and more & 11 & 8.4 \\
\hline
\end{tabular}

Source: Field data (2013).

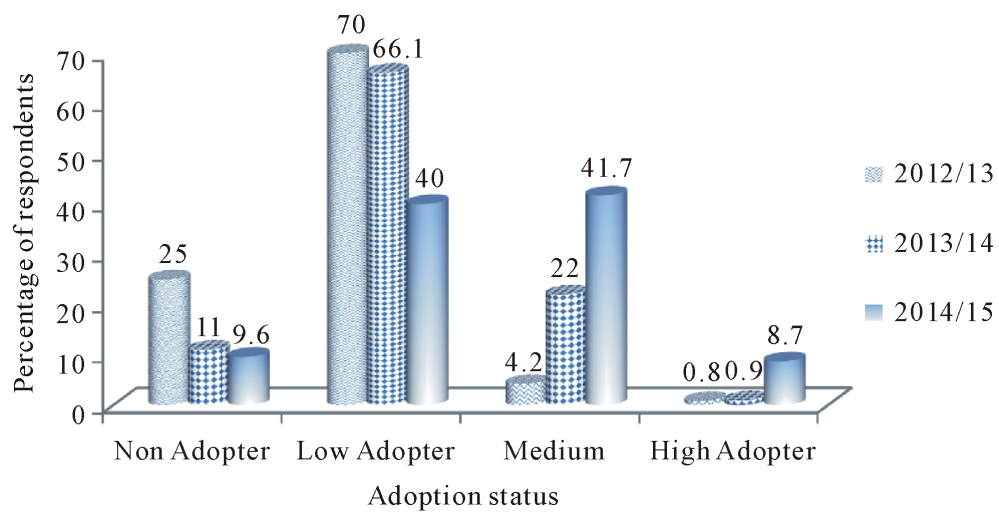

Figure 1. Three year adoption behaviour of some small scale cocoa farmers in a pilot microcredit scheme whose farms are classified as matured (i.e. from eight year to 30 years old). Source: Field data. $(\mathrm{N}=120)$

in high adoption from $0.8 \%$ in 2013 to $8.7 \%$ in 2015 could be attributed to the farmer education and access to credit. It is therefore hoped that continuous education and access to credit could increase adoption rate among small holder cocoa farmers.

\subsubsection{Farmer Age and Adoption Status}

The results indicates that the youth (20 - 40 years) were unable to make a medium score of adoption with some scoring low on adoption while others were non-adopters (Table 5). The picture is similar for the other age groups. However, only $0.8 \%$ of the respondents in the age group 41 - 60 could be classified as full adopters. In general, less than one percent of the respondents could be classified as full adopters who used all the CRIG recommended technologies being measured as a full package. This is a matter of concern for sustainable cocoa production which relies on the synergistic effect of composite recommendations.

\subsubsection{Educational Level and Adoption Behaviour}

Education did not seem to affect adoption. Ironically, the $0.8 \%$ of farmers that adopted the recommendations in full were all basic level graduates (Table 6). Out of the $70 \%$ that were classified as low adopters, a couple of 
Table 5. Farmer age and adoption status.

\begin{tabular}{|c|c|c|c|c|c|}
\hline \multirow{2}{*}{$\begin{array}{l}\text { Age of farmers } \\
\text { (years) }\end{array}$} & \multicolumn{4}{|c|}{ Percentage of respondents in adopter status } & \multirow{2}{*}{$\begin{array}{l}\text { Total no. of } \\
\text { respondents }\end{array}$} \\
\hline & Non-Adopter & Low & Medium & High & \\
\hline $20-40$ & 5.0 & 9.0 & 0.0 & 0.0 & 14 \\
\hline $41-60$ & 13.0 & 38 & 3.0 & 0.8 & 55 \\
\hline $60+$ & 7.0 & 23 & 0.8 & 0.0 & 31 \\
\hline Total & 25.0 & 70.0 & 3.8 & 0.8 & 100 \\
\hline
\end{tabular}

Source: Field data (2013).

Table 6. Respondents educational status and adoption levels.

\begin{tabular}{cccccc}
\hline \multirow{2}{*}{ Level of Education } & \multicolumn{5}{c}{ Percent of farmers in Adopter status managing matured farms } \\
\cline { 2 - 6 } & Non-Adopter & Low & Medium & High & Totals \\
\hline No formal education & 2.0 & 6.0 & 0.8 & 0.0 & 8.0 \\
Primary/JHS/Middle & 20.0 & 49.0 & 3.0 & 0.8 & 72.0 \\
Secondary/Vocational/Tech. & 3.0 & 12.0 & 0.8 & 0.0 & 17.0 \\
Tertiary education & 0.0 & 3.0 & 0.0 & 0.0 & 3.0 \\
Total & 25.0 & 70.0 & 4.0 & 0.8 & 100.0 \\
\hline
\end{tabular}

Source: Field data (2013) N = 120 .

them (3.0\%) had attained tertiary level education. Clearly, their educational status could not affect their adoption behavior positively as expected.

\subsubsection{Age of Farms and Adoption Status}

Results on farm age (Table 7) also showed that only $0.8 \%$ of farmers whose farms were fairly young (within the ages 8 - 15) were able to adopt all the CRIG recommended technologies as a package. But as the farm aged, adoption status decreased showing an inverse relationship. This requires further large scale studies to explore the relationship between farm age, some socio-economic factors and full adoption behavior of farmers nationwide.

\subsection{Selective Adoption Behavior of Farmers (Individual Recommendations)}

In analyzing the technologies individually, it was realized that the respondents were selective in their adoption behavior (Table 8). They explained that they did so based on their financial capabilities and priorities at the time. Most (57\%) of the respondents chose to weed 2 - 4 times per year compared to practices that demanded more capital like pests and diseases control with only $32 \%$ and $9 \%$ of the respondents adopting them respectively.

Some farmers did not bother at all about disease and/or pest control and perhaps did not also benefit from the government's policy on cocoa pests and disease control and hence recorded zero on that management practice. On fertilizer application, 57\% scored low, or did not apply fertilizer at all (43\%). None of the respondents had applied fertilizer on the three or four consecutive times as recommended by CRIG. This shows that they were ignorant of soil nutrient amelioration, and that it is probably the membership of the farmer associations that had exposed them to fertilizer use on cocoa farms. This reiterates the importance of encouraging farmers to form associations that will offer opportunity to be educated and facilitated to get access to fertilizer and other farm inputs.

\subsection{Constraints to High Adoption of CRIG-Recommended Technologies by Respondents}

Small scale farmers' ability to adopt the full package of CRIG recommendations is challenged by many socioeconomic factors. For this reason, about $63.9 \%$ indicated that they were unable to adopt the full package due mainly to financial and labour constraints (Table 9) although they very much appreciated the interactive effect 
Table 7. Age of farm * Adopter status.

\begin{tabular}{cccccc}
\hline \multirow{2}{*}{ Age of farm (years) } & \multicolumn{5}{c}{ Adopter status for farmers (\%) who own matured farm (8 to 30+ years) } \\
\cline { 2 - 6 } & Non-Adopter & Low & Medium & High & Totals \\
\hline 8 - 15 (Young) & 12.5 & 28.0 & 2.0 & 0.8 & 43 \\
16 - 30 (Mature) & 7.5 & 33.0 & 2.0 & 0.0 & 43 \\
31 \& above (Old farms) & 5.0 & 9.0 & 0.0 & 0.0 & 0.8 \\
Total & 25.0 & 70.0 & 4.0 & & 100.0 \\
\hline
\end{tabular}

Source: Field data (2013) N = 120.

Table 8. Distribution of selective adoption behavior of farmers on individual recommendations (Percentages of respondents).

\begin{tabular}{|c|c|c|c|c|c|}
\hline \multirow{2}{*}{ Recommended Technologies } & \multicolumn{5}{|c|}{ Adoption status of farmers (\%) } \\
\hline & High & Medium & Low & Non-Adopter & Total \\
\hline Weeding (2 - 4 times/year) & 57 & 34 & 9 & 0 & 100 \\
\hline Spraying Capsid (4 times/year) & 32 & 47 & 18 & 3 & 100 \\
\hline Spraying black pod (6 - 9 times/year) & 9 & 21 & 61 & 9 & 100 \\
\hline Pruning (2 times/year) & - & - & - & 8 & 8 \\
\hline Apply fertilizer (1/year for 3 to 4 years continuously) & 0 & 0 & 57 & 43 & 100 \\
\hline Mistletoe control (2 - 4 times/year) & 5 & 9 & 65 & 21 & 100 \\
\hline
\end{tabular}

$\mathrm{N}=131 *$ (including 11 farmers whose farms were classified as very young farms ( 0 - 7 years). Source: Field data (2013).

Table 9. Farmers constraints to high/full adoption.

\begin{tabular}{cc}
\hline Constraints & Percentage (\%) \\
\hline Financial \& labour difficulties & 63.9 \\
Other reasons including children's education & 18.6 \\
Lack of knowledge & 12.4 \\
Failure of owners to assist caretakers financially & 5.2 \\
\hline
\end{tabular}

Source: Field data (2013) N = 97.

of all the technologies as a package. This is where nurturing their personal savings culture is of essence to them and to sustainable cocoa production.

Difficulty in getting labour to do farm work, especially, considering farmers' old age is another constraint. Respondents explained that small-scale mining locally called galamsey is now seriously competing for labour of the youth who could be hired for farm work in their communities. Galamsey seem to offer the youth easy and quick money unlike farm activities which are seen as strenuous and time consuming. It was found that while wage for farm work per man day cost between GH\$7.00 and GH\$12.00, one’s labour for galamsey i.e. illegal small scale mining, can earn multiple times that of farm work depending on one's involvement.

There are also other factors such as farmers' multiple farms, children's education, lack of credit and social obligations like cost of funerals which compete for farmers' income and thus affect their ability to adopt the full package of recommendations. The solution will then be facilitating access to convenient and affordable farm credit in the form of input and cash to hire labour.

\section{Conclusion and Recommendation}

The results of this study have shown that full adoption of recommended CRIG technologies is still low despite 
the proven benefits. Although the adoption status of most of the respondents is low, it can be admitted that the results portray a realistic picture of full technology adoption by small-scale cocoa farmers. Much as farmers appreciate the benefit of full adoption, they are nonetheless, challenged by many socio-economic factors that need policy intervention including the availability of sustainable credit to hire labour and purchase farm inputs. It is therefore recommended that this study is carried out in all the cocoa growing regions in Ghana with a large sample size in order to have a nationwide representation of farmers' adoption behavior of recommendations for cocoa production for policy direction. There is also the need to identify current major constraints to full adoption at the national level in order to institute interventions that can boost positive change in farmers' adoption behaviour. It is also important to draw lessons from this study to find out whether the many certification bodies that provide standards for farmers are having any impact on adoption behavior, especially, those farmers that receive credit for inputs and additional income through the payment of premium.

\section{Acknowledgements}

The Authors wish to express their gratitude to the Management of Cocoa Research Institute of Ghana (CRIG) for the support for this research work. This publication number CRIG/002/2014/044/007 is published by kind permission of the Executive Director.

\section{References}

[1] Bulír, A. (2002) Can Price Incentive to Smuggle Explain the Contraction of the Cocoa Supply in Ghana? Journal of African Economies, 11, 413-439. http://dx.doi.org/10.1093/jae/11.3.413

[2] CRIG (2010) Cocoa Manual: A Source Book for Sustainable Cocoa Production. Cocoa Research Institute of Ghana, New-Tafo, Akim.

[3] International Cocoa Organization (ICCO) (2007) Annual Report 2005/2006. ICCO, London.

[4] Opoku, I.Y., Gyasi, E.K., Onyina, G.K., Opoku, E. and Fofie, T. (2007) The National Cocoa Diseases and Pests Control (CODAPEC) Programme: Achievements and Challenges. Proceedings of 15th International Cocoa Research Conference, San Jose, 9-14 October 2006, 1007-1013.

[5] Baah, F., Anchirinah, V. and Amon-Armah, F. (2011) Soil Fertility Management Practices of Cocoa Farmers in the Eastern Region of Ghana. Agriculture and Biology Journal of North America, 2, 2151-7517.

http://dx.doi.org/10.5251/abjna.2011.2.1.173.181

[6] Henderson, C.P. and Jones, A.P. (1990) Analysis of Constraints to the Adoption of CRIG Recommendations in Offinso Districts: Results and Discussion. CRIG Farming Systems Unit Research Paper No. 1, Cocoa Research Institute of Ghana (CRIG) Tafo, 15.

[7] Donkor, M.A., Henderson, C.P. and Jones, A.P. (1991) Survey to Quantify Adoption of CRIG Recommendations. Farming Systems Unit Research Paper No. 3, Cocoa Research Institute of Ghana (CRIG), New Tafo, 29.

[8] Asante, E.G. (1992) Benefit-Cost Analysis of CRIG Recommended Technologies in Relation to Farmer Adoption Patterns and Implication for the Cocoa Industry in Ghana. A Final Report Submitted to the Research Committee, Cocoa Research Institute of Ghana (CRIG), Akim Tafo.

[9] Asamoah, M. (2001) The Influence of Socio-Economic and Cultural Factors on the Adoption of CRIG Recommended Technologies. Thesis Submitted to the School of Research and Graduate Studies, Legon in Partial Fulfillment of Master of Philosophy Degree, University of Ghana, Legon Boundary.

[10] Aneani F., Anchirinah, V.M., Owusu-Ansah, F. and Mercy, A. (2012) Adoption of Some Cocoa Production Technologies by Cocoa Farmers in Ghana. Sustainable Agriculture Research, 1, 103-117. http://dx.doi.org/10.5539/sar.v1n1p103

[11] MASDAR (1998) Socio-Economic Study of Cocoa Farming Communities in Ghana. Ghana Cocoa Board/MASDAR International Consultants.

[12] Baah, F. and Asamoah, M. (2005) An Insight into Gender Issues in Cocoa Production in Ghana. Proceedings of 14th International Cocoa Research Conference, Accra, 13-18 October 2003, 1201-1206.

[13] Asamoah, M. (2007) Empowering Women through Self-Help Microcredit Schemes: A Model for Women Cocoa Farmers in Ghana. Proceedings of 15th International Cocoa Research Conference, San Jose, 9-14 Octomber 2006, 17431748.

[14] Asamoah, M., Owusu-Ansah, F., Anchirinah, V., Aneani, F. and Agyapong, D. (2013) Insight into the Standard of Living of Ghanaian Cocoa. Greener Journal of Agricultural Sciences, 3, 363-370. 